\title{
Uma proposta de recomendações para a elaboração de mapas para o Exame Nacional do Ensino Médio (ENEM): projetando tendo em vista sua descrição oral para cegos
}

\author{
A proposal of recommendations for the preparation of \\ maps for the National High School Examination (ENEM): \\ projecting in view of its oral description for the blind
}

Fernanda Domingues, Claudia Mara Scudelari de Macedo

mapas, cegos, descrição

\begin{abstract}
É direito do cego o acesso à universidade e cargos públicos. Para tal, os processos seletivos precisam adaptar-se para atender essa demanda. No Exame Nacional do Ensino Médio (ENEM), que vem crescendo exponencialmente e garantindo o acesso de muitos estudantes ao ensino superior, é disponibilizado para o candidato cego a prova em braille e o ledor, voluntário que se candidata para transcrever respostas, redações, e a descrever oralmente imagens. No entanto, várias queixas sobre a atuação desse voluntário se somam, principalmente sobre a descrição de figuras. Considerando os mapas como imagens de grande importância no exame, com ocorrência de no mínimo 5 por edição, questiona-se: como aprimorar o design de mapas contidos em provas de processos seletivos públicos inclusivos brasileiros, de maneira que a sua descrição oral seja acurada para candidatos cegos? Através das recomendações sobre a utilização das variáveis gráficas de Bertin (1983), somadas às recomendações da área de Acessibilidade, e às opiniões de quatro voluntários que já atuaram como ledores no ENEM, o presente trabalho propõe recomendações para a elaboração de mapas a serem descritos oralmente para candidatos cegos no exame.
\end{abstract}

maps, blind, description

In It is the right of the blind to have access to university and to public office. To do so, selective processes need to adapt to meet this demand. The National High School Exam - ENEM, which is growing exponentially and ensuring access to many higher education - is available to the blind candidate to test Braille and ledor, volunteer candidate to transcribe answers, essays, and to describe images for the blind candidates. However, several complaints about the performance of this volunteer add up, especially with regard to the subjective description of figures. Considering the maps as great importance in the examination of images, occurring in at least 5 per issue, the question is: how to improve the design of maps contained evidence of Brazilian inclusive public selection processes, so that their oral description is accurate to blind candidates? Through the recommendations on the use of the graphical variables of Bertin (1983), together with the recommendations of the area of Accessibility, and the opinions of two volunteers who have acted as ENEM lenders, this paper proposes recommendations for the elaboration of maps to be described orally to blind candidates on the exam. 


\section{Introdução}

Por muitos anos, pessoas com deficiência visual foram consideradas inaptas para qualquer atividade física ou intelectual. Somente a partir do final da década de 1950 que a integração dos cegos veio a se tornar uma política pública. Em 1990, despontaram discussões sobre a educação inclusiva, na qual as peculiaridades de cada indivíduo vieram a ser respeitadas no processo pedagógico. A partir disso, verificou-se aumento no ingresso das pessoas com deficiência em escolas, universidades e cargos públicos (CASTRO, 2011).

A Lei no 8.112, de 11 de dezembro de 1990 traz no artigo $5^{0} \$ 2^{\circ}$ o direito das pessoas com deficiência à inscrição em processos seletivos públicos, como por exemplo, vestibulares de Universidades Federais, e provas para o preenchimento de cargos em repartições públicas, firmando $20 \%$ das vagas exclusivamente a essa população (BRASIL, 1990). Cada edital estabelece como essas pessoas serão inseridas e quais aparatos serão disponibilizados durante a prova, sendo um direito do candidato cego, no mínimo, a prova em Braille e um ledor - pessoa que descreve a prova e as imagens para o candidato com deficiência visual. A presença do ledor também é um direito firmado por lei, conforme decreto 5.296, inciso 59 de 02 de dezembro de 2004 (BRASIL, 2004).

Dentre os processos seletivos públicos brasileiros que incluem candidatos cegos, destaca-se o ENEM, criado pelo Instituto Nacional de Estudos e Pesquisas Educacionais Anísio Teixeira (INEP), e que vem desde 2009 facilitando a entrada de muitos estudantes ao ensino superior. Estima-se que até 2020, mais de 300 universidades no Brasil utilizarão o ENEM como processo seletivo para o preenchimento de suas vagas (SILVEIRA; BARBOSA; SILVA, 2015). Nesse exame, além de uma hora a mais para a realização da prova, o candidato cego conta com a prova em braille, e com o ledor. Apesar desses recursos oferecidos, entre 2016 e 2017 as inscrições de alunos com cegueira caíram mais de 30\% no exame (INEP 2016; 2017). Várias são as queixas que se somam em relação à apresentação da prova, e principalmente aos auxílios de leitura e transcrição.

Os ledores do ENEM são cidadãos brasileiros que se voluntariam para trabalhar nos dois dias do exame, recebendo gratificação monetária determinada pela organização do concurso. De acordo com regulamento publicado pelo INEP em 2002, é obrigatório que possuam ensino médio completo, e que realizem curso de capacitação disponibilizado pela própria organização do exame (INEP, 2002).

Apesar de se apresentarem como um recurso amplamente utilizado em processos seletivos brasileiros, Fiori e Manzini (2010) chamam a atenção para os problemas que podem ser causados pela atuação de voluntários ledores. Segundo os autores, a interpretação de imagens através da leitura de outra pessoa trata-se de um processo complexo, visto que leva em consideração as formas e impressões subjetivas que a visão das figuras desperta em quem as descreve. No ENEM, a prova utilizada pelo ledor formata-se de maneira semelhante 
à prova escrita, acrescentando-se ocasionalmente a descrição das imagens (INEP, 2002). No entanto, de acordo com Diniz (2013), nem todas as imagens possuem descrição, ficando nesse caso a critério do ledor utilizar a própria imaginação.

Como apontado por Santos (2011), a utilização de imagens estáticas como gráficos, charges e ilustrações em processos seletivos por muitas vezes torna-se essencial para a interpretação correta das questões, e consequentemente seu acerto. Dentre as inúmeras imagens que se encontram nas provas do ENEM, encontram-se os mapas. Em levantamento realizado a partir do novo formato do exame adotado desde 2009, observou-se a incidência desse tipo de imagem em todas as provas, com ocorrência de no mínimo cinco mapas por edição. Observou-se também que a sua utilização não se restringe a área de geografia. Encontraram-se mapas como elemento fundamental na elaboração de redações, por exemplo.

Estudos no Design da Informação como o de Loch (2008) trazem importantes considerações sobre a adaptação de mapa para cegos. No entanto, através de Revisão de Bibliográfica Sistemática, percebeu-se uma lacuna de estudos que abordassem a apresentação de mapas em processos seletivos a serem descritos oralmente por ledores para candidatos cegos.

Assim, questiona-se: como aprimorar o design de mapas contidos em provas de processos seletivos públicos inclusivos brasileiros, de maneira que a sua descrição oral seja acurada para candidatos cegos? Os mapas foram selecionados para o estudo principalmente por: (a) sua importância na percepção do espaço pelo cego; (b) sua presença constante desde o primeiro ciclo escolar; (c) pela importância de sua descrição oral adequada e (d) pela lacuna sobre estudos que abordem descrições orais de mapas para cegos.

Isto posto, através das recomendações sobre a utilização das variáveis gráficas de Bertin (1983), somadas as recomendações encontradas na área da Acessibilidade, e às opiniões de quatro voluntários que já atuaram como ledores do ENEM, o objetivo do presente trabalho é propor recomendações para a elaboração de mapas a serem descritos para cegos no exame.

Para tal, primeiramente realizou-se revisão de literatura acerca das abordagens de Bertin (1983), e de teóricos da acessibilidade que abordam o assunto, seguida de entrevista semi-estruturada com quatro voluntários ledores.

O artigo se inicia discorrendo sobre as variáveis gráficas de Bertin (1983), e as recomendações elaboradas a partir delas por MacEachren (1994). Na sequência, listam-se os principais achados referentes ao tema na área da acessibilidade. Em seguida, os principais pontos da entrevista semi-estruturada com os ledores são apresentados, finalizando-se com a proposta do conjunto de recomendações, seguido por sua discussão e conclusão. 


\section{Os mapas}

Os mapas para "ver" foram uma das preocupações de Bertin $(1983,1986)$, que deixou como maior legado a sistematização das Variáveis Visuais ou Variáveis Gráficas, quais foram identificadas como modulações visuais no plano das primitivas gráficas: ponto, linha e área. Em "Semiology of Graphics" o autor distinguiu informações como as localizações $x-y$ no plano, forma, tamanho, orientação, cor, valor, e granulação, popularmente conhecida como textura, como demonstradas na Figura 1 a seguir a partir da aplicação sobre as primitivas gráficas:
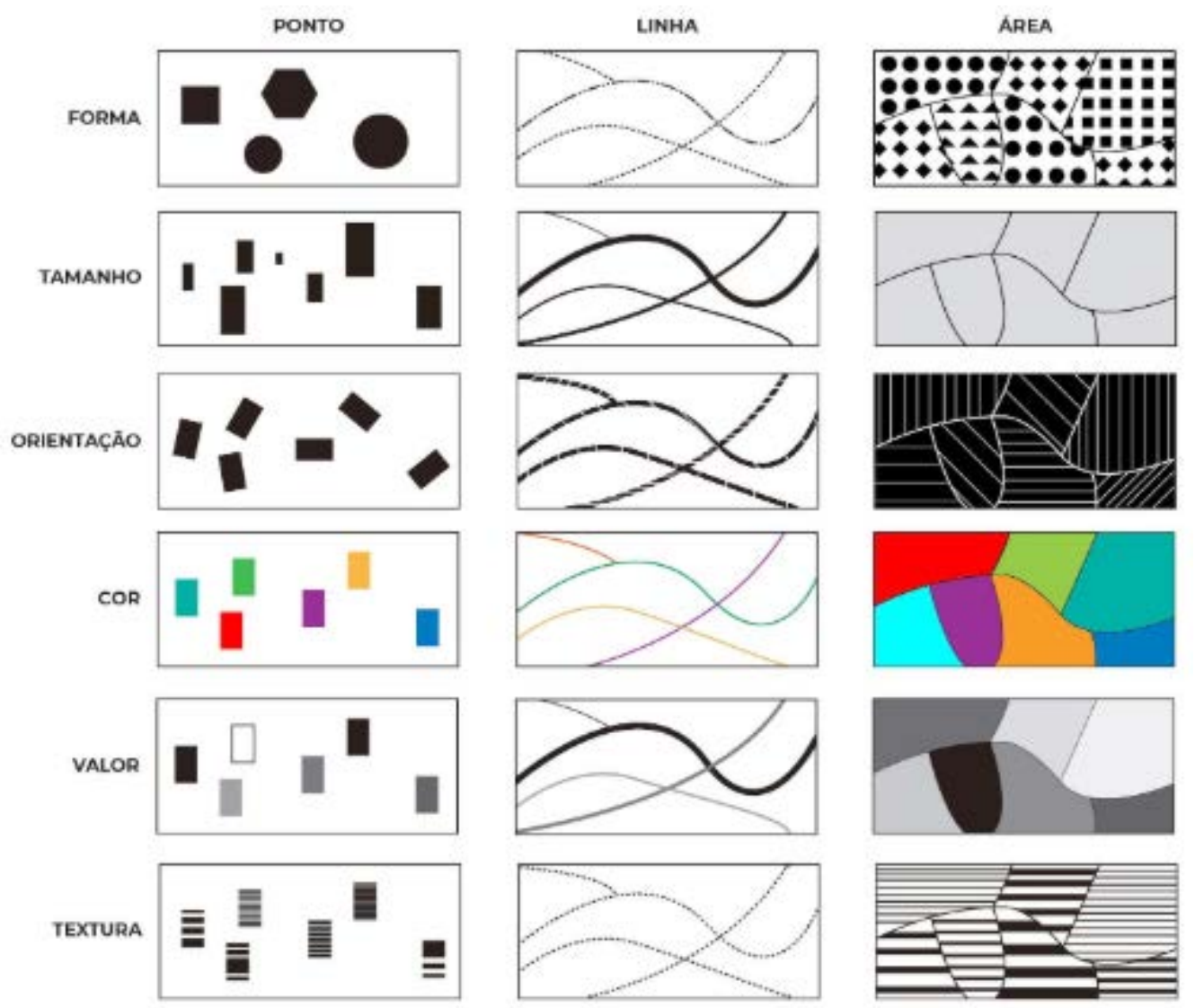

Figura 1 Variáveis Gráficas. Fonte: adaptado de Bertin (1983).

Para cada variável gráfica, Bertin (1983) também fez apontamentos para sua utilização de maneira mais eficaz na cartografia. Segundo o autor, a utilização da simbolização através da forma é recomendada para casos de representação de diferenças nominais, ou seja, diferenças entre os tipos de objetos representados. Já a uso de diferenças criadas pela variação da orientação dos elementos são muito visíveis e podemos aproveitá-las de forma diferenciada entre as variáveis nominais. Segundo estudos anteriores, o autor sugeriu que alguns neurônios são seletivamente sensíveis a diferentes orientações.

Já utilização da cor, segundo Bertin (1983) é recomendada principalmente para diferenciações nominais, bem como a forma. No entanto, MacEachren (1994) destaca que a eficácia desse recurso 
é inversamente proporcional ao tamanho: pequenos pontos ou linhas que se diferenciem somente por suas cores no mapa não serão facilmente percebidos. Outro erro comum cometido por cartógrafos e designers é a aplicação das matizes como recurso de diferenciação entre dados numéricos ordinais. Há uma ordem lógica entre tons definida pelo espectro magnético. Contudo, grande parte da população desconhece tal ordem, e mesmo para os que conhecem, diferenças entre valores de cores ainda são desafiadoras.

Prosseguindo com as indicações para a utilização das variáveis gráficas, Bertin (1983) aponta que o valor vem com o objetivo de apresentar uma ordem visual óbvia, e pode ser entendida, de acordo com MacEachren (1994, p.25) "a pureza de um tom".

Por fim, Bertin (1983) refere-se à textura como a frequência espacial dos componentes de um padrão. Como é definida apenas para padrões, são necessárias áreas relativamente grandes para que as diferenças de textura sejam óbvias. É, portanto, mais adequada para a diferenciação entre as áreas.

Com o intuito de aprofundar a obra de Bertin (1983), MacEachren (1994) elaborou um guia que possa ser utilizado por todos os interessados em produzir mapas fundamentados e que possam ser compreendidos pelo grande público, utilizando-se das variáveis gráficas de Bertin, e suas recomendações de uso.

Assim, as recomendações para a utilização das variáveis gráficas de MacEachren (1994) estruturam-se de acordo com o nível de percepção: nível de percepção qualitativo, nível de percepção ordenado e nível de percepção quantitativo. Os dados que se enquadram no nível qualitativo descrevem uma relação de similaridade ou diversidade e nenhuma operação matemática pode ser estabelecida entre essas classes. No nível ordenado, os dados mantêm uma relação de hierarquia entre as classes, pois as classes de feição se ordenam espontaneamente, porém, sem caracterizar qualquer manifestação de proporção, visto que não há valores numéricos associados às classes. Assim, ao comparar duas classes A e B é possível apenas estabelecer que A é maior (ou menor) que B, sem afirmar o valor dessa magnitude (MACEACHREN, 1994). Por fim, os dados de nível quantitativo são oriundos de uma contagem, uma estatística ou uma medição. Por exemplo, os dados de população são provenientes de uma contagem, a temperatura em uma cidade advém de uma medição e a porcentagem de mulheres grávidas com mais de 30 anos uma relação/proporção/razão. Na Figura 2 a seguir, a partir de mapas coletados das provas do ENEM, ilustram-se os três níveis: 

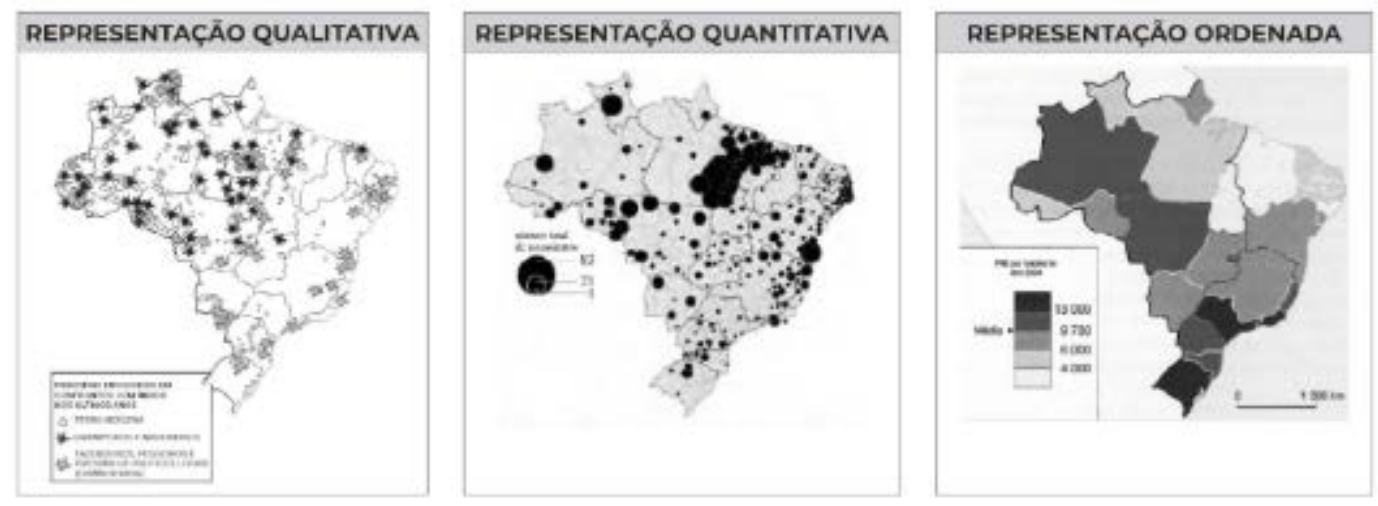

Figura 2 Representações qualitativa, quantitativa e ordenada. Fonte: adaptado de Brasil (2009; 2013 ).

A Figura 3 a seguir demonstra, portanto, as recomendações para a utilização das variáveis gráficas de acordo com os níveis de percepção, utilizando (B) para bom, (M) para médio e (P) para pobre:

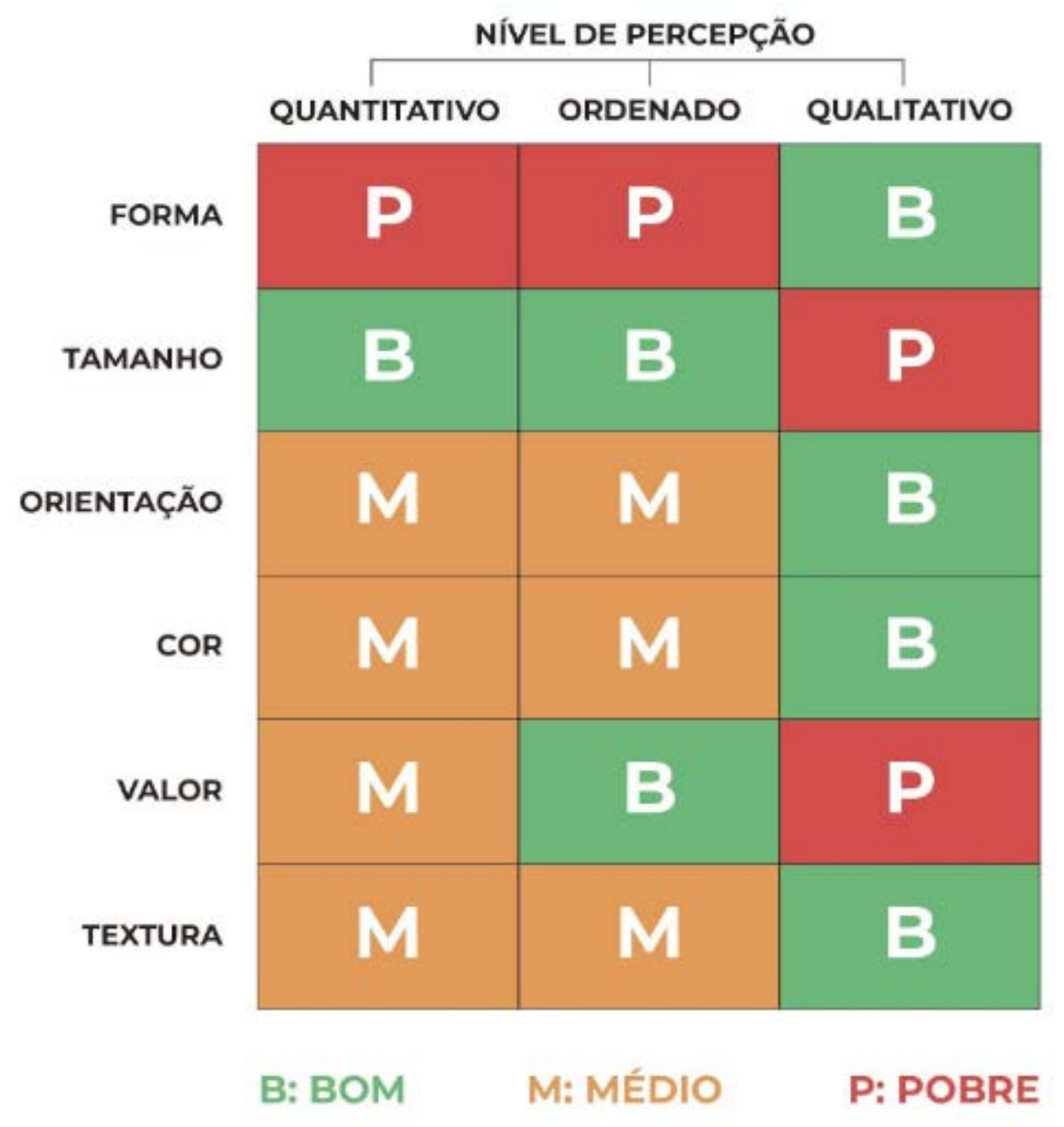

Figura 3 Recomendações para a utilização das Variáveis Gráficas. Fonte: adaptado de MacEachren (1994). 
Ressalta-se que os níveis "Bom", "Médio" e "Pobre" foram definidos dessa maneira pelo autor de acordo com sua eficácia. Assim MacEacheren (1994) cria, através dessa designação, uma escala de mensuração a que se pretende aplicar as variáveis gráficas.

Após o levantamento das recomendações para a utilização das variáveis gráficas, procurou-se encontrar referências que citassem os mesmos aspectos do ponto de vista da área da acessibilidade, abordando assim o contexto de mapas descritos para cegos. Os autores que trouxeram apontamentos adequados ao tema são descritos na sequência.

O National Center for Accessible Media (NCAM) é o maior produtor de programas para distribuição de conteúdo nos Estados Unidos, tendo, desde sua fundação, especializado-se também na disponibilização de mídia e tecnologia assistiva para pessoas com deficiência. Explorando políticas de acessibilidade, o centro disponibilizou o texto "Guidelines for Describing Images for Assessments" (2018) ou em livre tradução "Diretrizes para descrever imagens para avaliações". No texto, a organização aponta também recomendações para mapas que fazem parte de provas que incluiem cegos, sendo esses tópicos extraídos para o presente trabalho.

Em "NWEA - Image Description Guidelines for Assessments" (2017) ou em tradução livre "NWEA - diretrizes para a descrição de imagens em avaliações”, a Northwest Evaluation Association (NWEA) em parceria com a NCAM desenvolveu manual de instruções para auxiliar ledores em processos de avaliação. Além das instruções técnicas para leitura, o material também traz recomendações para a composição das imagens de maneira que sejam de fácil compreensão para o estudante e para o leitor. Ao se referir aos mapas, a organização recomenda, dentre outros pontos, a utilização de vocabulário específico para os exames, para que assim se empregue uma mesma linguagem durante toda a prova.

Por fim, dentro dos destaques dos achados bibliográficos da área da acessibilidade, destaca-se os estudos de Perkins (2008). Segundo o autor, a pesquisa sobre o uso do mapa até o começo dos anos 2000 focou-se amplamente em abordagens cognitivas, e subestimou o significado de preocupações contextuais mais amplas associadas às culturas nas quais a cartografia opera. Enquanto isso, o ato de projetar mapas está sendo popularizado, e as pessoas estão criando e empregando seus próprios mapas ao invés de confiar em cartógrafos. Assim, o Perkins (2008) enfatiza a necessidade de repensar o uso do mapa como um conjunto de atividades diárias praticadas em contextos do mundo real, utilizando-se para isso metodologias das ciências sociais. Dentro do contexto da prova, um dos fatores que devem ser considerados é principalmente a cultura de quem descreve os mapas, o ledor.

O levantamento se deu em 5 bases de dados, e os achados referentes exclusivamente as recomendações para a elaboração de mapas para descrição oral para cegos são demonstrados na Figura 4 a seguir: 


\begin{tabular}{|c|c|}
\hline RECOMENDAÇĀO & AUTOR(ES) \\
\hline $\begin{array}{l}\text { Respeitar a ordem de apresentaçăo entre as informaçóes: } \\
\text { enunciado, mapa e alternativas }\end{array}$ & NCAM (2009) \\
\hline $\begin{array}{c}\text { Os mapas devem manter o mesmo padrào de layout } \\
\text { ao longo do documento }\end{array}$ & $\operatorname{NCAM}\{2009\}$ \\
\hline Usar vocabulário cartográfico especifico & NWEA (2017) \\
\hline Incluir sempre que possivel a Rosa dos Ventos & NWEA (2017) \\
\hline $\begin{array}{l}\text { O idioma utilizado deve ser compativel ao } \\
\text { do ledor e candidato }\end{array}$ & NWEA $(2017)$ \\
\hline $\begin{array}{l}\text { Considerar como fatores contextua is ao se projetar um } \\
\text { mapa: mobilidade, visualizaçăo, onde a leitura do mapa ocorre, } \\
\text { tempo, contexto social, interatividade do meio e retórica }\end{array}$ & Perkins $(2008)$ \\
\hline $\begin{array}{c}\text { Fatores culturais devem desempenhar um papel maior } \\
\text { no projeto de representaçóes e interfaces } \\
\text { usadas na geovisualizaçảo }\end{array}$ & Perkins (2008) \\
\hline $\begin{array}{l}\text { Os ledores devem ter acesso a atlas } \\
\text { e dicionarios como material de apoio }\end{array}$ & Perkins (2008) \\
\hline
\end{tabular}

Figura 4 Achados na revisão de literatura. Fonte: as autoras (2018).

\section{Consulta a ledores}

Seguindo a coleta de informações a respeito de recomendações sobre os mapas, realizou-se entrevista semi-estruturada com quatro ledores, a fim de se explorar suas experiências, além de coletar opiniões sobre como os mapas podem ser apresentados de forma eficiente para o trabalho de descrição para cegos.

O número de voluntários escolhidos seguiu o que Given (2008) chama de amostra não probabilística, técnica comum para a escolha de amostra em pesquisas qualitativas, onde o pesquisador usa seu próprio julgamento para a escolha dos participantes. Os voluntários foram escolhidos por:

- Conveniência: em locais de fácil acesso;

- Bola de neve: indicação de participantes através de voluntários já recrutados;

- Propósito: participantes que se encaixam nos critérios de seleção definidos pelo pesquisador. 
Para os ledores, o principal local para busca de voluntários foi o Instituto Brasileiro de Geografia e Estatística (IBGE) de Curitiba, que, como indicado pelo primeiro entrevistado, concentra funcionários que já participaram como ledores em processos seletivos públicos brasileiros.

Foram selecionados ledores que:

- Já foram voluntários em processos seletivos anteriores, atendendo candidatos com deficiência visual;

- Independente de gênero;

- Que estejam cursando ou tenham finalizado o Ensino Médio;

- Independente de idade, desde que atendam os critérios acima mencionados.

Os entrevistados relataram suas experiências como ledores desde o curso de preparação até sua atuação nos exames. Por conveniência, as entrevistas ocorreram em duplas: entrevistou-se os Ledores 1 e 2 concomitantemente, e em um segundo momento os Ledores 3 e 4 . Seus perfis são ilustrados na Figura 5 a seguir:
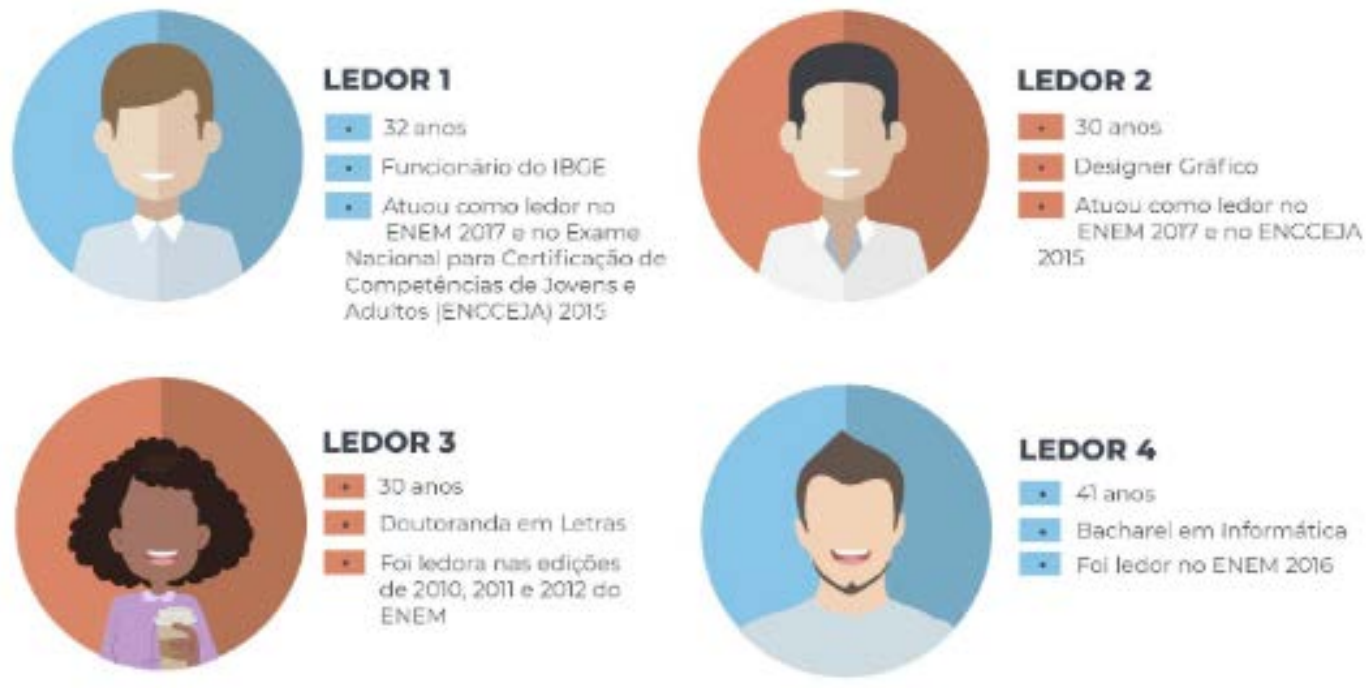

Figura 5 Perfil dos ledores entrevistados. Fonte: as autoras (2018).

Como observado em seus perfis, os voluntários atuam em áreas não relacionadas diretamente aos temas específicos abordados pelo ENEM ou pelo ENCCEJA, o que foi apontado de imediato pelos ledores como condição que gerou dificuldade. Como mencionou o Ledor 2 ao ser questionado sobre sua área de formação:

1 Entrevista concedida por 1, Ledor; 2 , Ledor. Entrevista I. [nov. 2017]. Curitiba, 2017. 1 arquivo .mp3 (90 minutos)
É, eu sou formado em design gráfico, e também não tem nada a ver mesmo. Até para mim foi um grande desafio, [...] imagine você ter que ficar lendo aquelas fórmulas matemáticas, descrevendo as imagens e tudo mais. [...] Ah, outra coisa que eu achei muito difícil foi o mapa que apareceu. [...] A sorte é que a gente tinha até um conhecimento geográfico, então a gente meio que sabia se virar (informação verbal) ${ }^{1}$.

Sobre a escolha dos ledores e sua relação com as áreas abordadas no ENEM, o Ledor 3 argumentou: 
2 Entrevista concedida por 3, Ledor; 4 , Ledor. Entrevista II. [mar. 2018]. Curitiba, 2018. 1 arquivo .mp3 (75 minutos).
Nós éramos indicados, não era um processo aberto. Eu fazia um trabalho junto a pró-reitoria da minha universidade, então eu fui indicada. Quem me indicou me conhecia, sabia o interesse que eu tinha por essas questões de acessibilidade, sabia que eu era fluente em inglês, essas coisas. Não era pelo dinheiro, era mais pelo cuidado e interesse com aquele trabalho. E eu leria para pessoas que tivesse escolhido o inglês como língua estrangeira. Então tinha essa questão da indicação e do interesse da pessoa também (informação verbal)². Ao discorrerem especificamente sobre os mapas que foram descritos por ambos nos exames, várias queixas foram relatadas. A primeira foi em relação ao tamanho dessas imagens: segundo os ledores, muitas, além de apresentarem um excesso de informação, exibiram-se de tamanho inferior, dificultando a leitura das legendas, principalmente.

Outro aspecto que coletou uma série de queixas foi o uso extensivo da textura como variável gráfica para a distinção entre áreas. Como queixou-se o Ledor 2:

[...] e a prova em preto e branco, e a gente tinha que descrever as áreas que estavam marcadas ali. Por exemplo, tinha umas que estavam pintadas com pontinhos, outras que estavam pintadas com mais pontinhos, e outras que estavam com riscos, e a gente precisava descrever tudo isso pra ele. Então eu falei assim: "aqui temos um mapa do Brasil, na região Sul ele está marcado com uns pontinhos maiores, perto do Rio de Janeiro e Espírito Santo está marcado com risquinhos, e no nordeste com pontinhos menores". Nossa, e isso foi muito complicado, porque a gente não tinha o mapa original para descrever. Então a gente teve que descrever do nosso jeito. Se ele entendeu, eu não sei. Essa foi uma das questões que o candidato respondeu de qualquer jeito, provavelmente porque ele teve muita dificuldade em entender a descrição sobre o mapa, até porque nesse caso não recebemos a prova do ledor com a descrição. [...] Todas as legendas eram com texturas, e as bolinhas eram muito parecidas, e ler baseado na legenda, que teoricamente é o certo a se fazer, fica muito complicado (informação verbal) ${ }^{1}$.

Uma consideração que se comentou diversas vezes também foi a real necessidade dos mapas e imagens como um todo nos exames. Os voluntários se queixaram, primeiramente, que as provas são simplesmente adaptadas de acordo com as oferecidas aos demais candidatos, que enxergam. Assim, adapta-se um conteúdo extremamente visual, o que não é aplicado a realidade daqueles que não enxergam. O resultado é a aplicação de imagens que, em muitos casos, estão presentes na prova apenas por um aspecto estético, não sendo fundamentais para a resolução das questões. Como comentou o Ledor 1 :

É, mas eu acho assim, para muitas questões não é tão importante assim o visual, porque na verdade na interpretação do enunciado já dá para resolver, não precisava nem ter mapa, sinceramente. Você precisa só interpretar o enunciado corretamente (informação verbal) ${ }^{1}$.

O tempo de duração das provas também foi apontado pelos voluntários como insuficiente, mesmo quando os candidatos 
solicitaram a hora adicional garantida por lei, e pelos editais do ENEM e do ENCCEJA. Segundo os ledores, o processo de leitura prévia do material e seleção do que é realmente necessário para o candidato despende muito tempo e capacidade cognitiva dos mesmos, sendo apenas a hora adicional insuficiente.

Quanto ao delongamento para interpretação das informações, os ledores destacaram os mapas como imagens dificultosas nos exames, principalmente por apresentarem um "excesso de conteúdo a ser dito" (informação verbal) ${ }^{1}$. O Ledor 2 sugeriu:

Acho que é eles indicarem melhor o que precisa ser descrito do mapa, relacionando com a questão. [...] Aí sim fica mais fácil para o ledor, é mais fácil de bater o olho e entender. Não precisa ter uma imagem tão grande e cheia de informação para perguntar uma coisinha. [...] Porque a gente não pode só olhar friamente para a imagem, tem que olhar tudo para saber como descrever as imagens (informação verbal) ${ }^{1}$.

De acordo com todos os apontamentos levantados em entrevista, elaborou-se a Figura 6 a seguir. Agruparam-se sugestões para aprimorar o processo de aplicação dos mapas, além de suas formas de representação.

\begin{tabular}{|c|c|}
\hline RECOMENDAÇÃO & LEDOR(ES) \\
\hline $\begin{array}{c}\text { Os mapas devem apresentar um tamanho mínimo de } \\
\text { acordo com o diagramação das provas, de maneira } \\
\text { que seja visivel e identificável pelo ledor }\end{array}$ & Ledores $1,2,3$ e 4 \\
\hline $\begin{array}{l}\text { Utilizar mapas quando estritamente } \\
\text { necessário para a resolução da questão }\end{array}$ & Ledores $1,2,3$ e 4 \\
\hline $\begin{array}{c}\text { As provas do ledor e do cego devem ser trabalhadas } \\
\text { individualmente, retirando-se o excesso de artifícios visuais } \\
\text { desnecessários presentes na prova comum }\end{array}$ & Ledores 1 e 2 \\
\hline $\begin{array}{c}\text { Tornar obrigatório o curso de capacitação para voluntários } \\
\text { que se inscrevem em processos seletivos públicos que } \\
\text { incluam candidatos com deficiência }\end{array}$ & Ledores 1 e 2 \\
\hline $\begin{array}{c}\text { A prova do ledor deve ser obrigatoriamente } \\
\text { disponibilizada, com todas as descriçôes necessárias } \\
\text { e para todos os tipos de deficiência }\end{array}$ & Ledores $1,2,3$ e 4 \\
\hline $\begin{array}{l}\text { Para candidatos que solicitam o auxilio-ledor, } \\
\text { disponibilizar mais de uma hora adicional }\end{array}$ & Ledores $1,2,3$ e 4 \\
\hline
\end{tabular}

Figura 6 Recomendações apontadas pelos ledores. Fonte: as autoras (2018). 


\section{Conjunto de recomendações}

Por fim, como resultado da primeira fase da pesquisa, tem-se o conjunto inicial de recomendações. Através da reunião dos achados encontrados na Revisão Bibliográfica e dos pontos sugeridos pelos ledores em entrevista, as recomendações são dividas em duas seções: recomendações para a aplicação das variáveis gráficas nos mapas, e recomendações para a apresentação dos mapas nos processos seletivos.

A primeira seção (Figura 7) constitui-se essencialmente da Figura 2, referente às recomendações para a utilização das variáveis gráficas de acordo com MacEachren (1994). Ao nível de percepção qualitativo da variável gráfica Textura, foram acrescentadas duas observações realizadas pelos ledores em entrevista: 
As recomendaç̧̄es abaixo têm o objetivo de orientar a elaboração de mapas para processos seletivos públicos brasileiros de maneira que sua descriçâo oral seja adequada para cegos.

Assim, apresentam-se duas seções:

Recomendaçōes para a aplicaçăo das variáves gráficas nos mapas

Recomendaçōes para a apresentação dos mapas nos processos seletivos

\section{RECOMENDAÇŌES PARA A APLICAÇÃO DAS VARIÁVEIS GRÁFICAS NOS MAPAS}

O quadro a seguir apresenta as recomendaçòes para a utilizaçäo das variáveis gráficas forma, tamanho, orientação, cor, valor e textura, de acordo com os niveis quantitativo, ordenado e qualitativo de percepção.

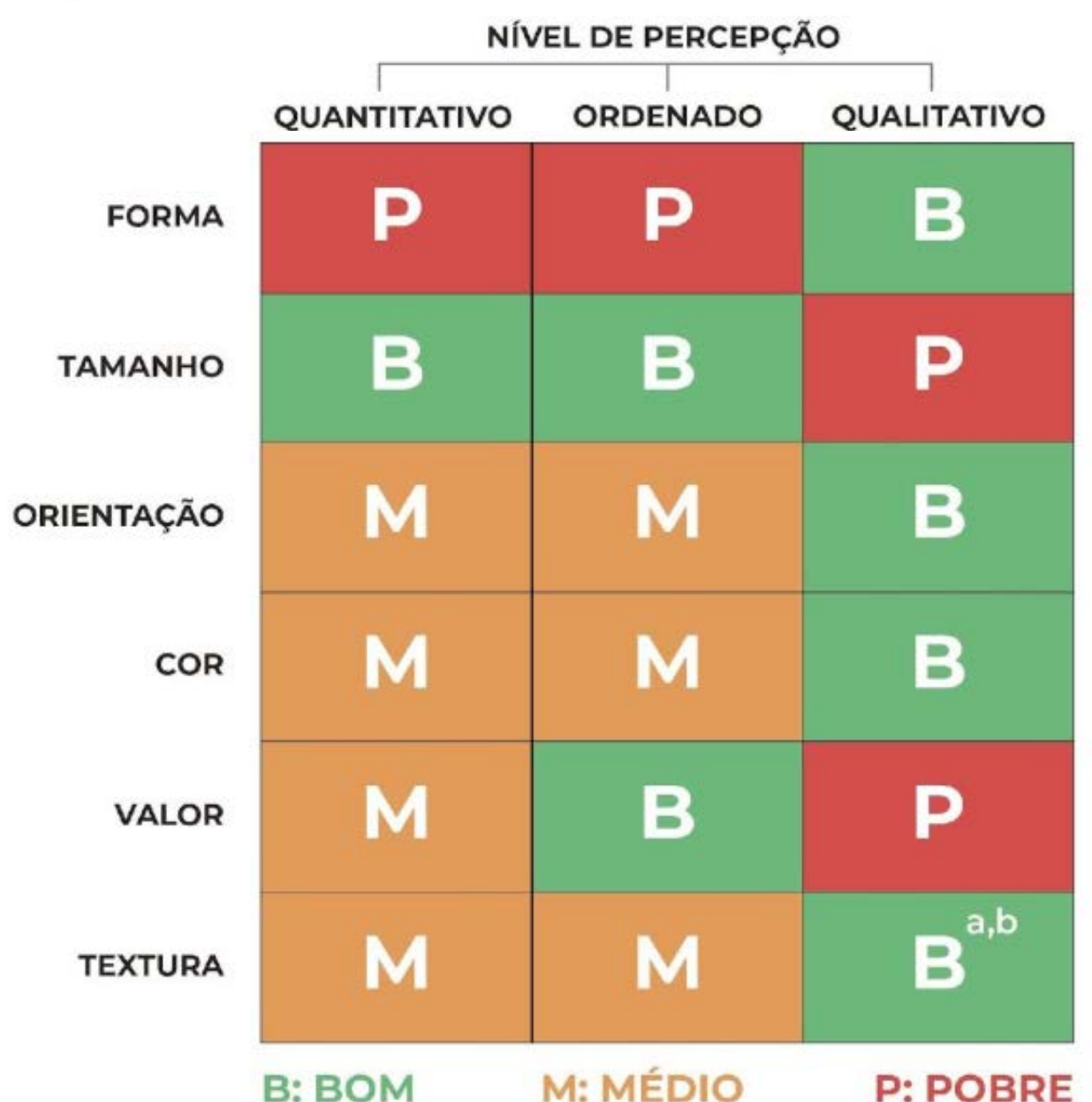

a: Ao utilizar texturas para distinguir áreas, o fazer em cores diferentes na prova do ledor ${ }^{1}$

b: Evitar a utilizaçāo de texturas similares entre $\mathrm{si}^{1}$

Fontes: Bertin (1983), MacEachren (1994), Informação verba| ${ }^{1}$

${ }^{1}$ Entrevista concedida por DESIGNER, Ledor; PORTUGUES; Ledor. Entrevista L. [nov. 2017]. Curitiba, 2017. 1 arquivo .mp3 (90 minutos).

Figura 7 Primeira página do conjunto de recomendações. Fonte: os autores (2018). 
A segunda seção "Recomendações para a apresentação dos mapas nos processos seletivos" agrupa as recomendações encontradas na área de acessibilidade, somadas às sugestões dos ledores fornecidas em entrevista, como demonstra a Figura 8 a seguir:

\section{RECOMENDAÇÕ̃S PARA A APRESENTAÇÃO DOS MAPAS NOS PROCESSOS SELETIVOS}

O quadro a seguir apresenta as recomendações para a apresentação dos mapas em processos seletivos de acordo com autores levantados durante à revisão bibliográfica e a entrevista.

\begin{tabular}{|c|c|}
\hline RECOMENDAÇÃO & AUTOR(ES) \\
\hline $\begin{array}{l}\text { Respeitar a ordem de apresentação entre as informações: } \\
\text { enunciado, mapa e alternativas }\end{array}$ & NCAM (2009) \\
\hline $\begin{array}{l}\text { Os mapas devem manter o mesmo padrão de layout } \\
\text { ao longo do documento }\end{array}$ & NCAM (2009) \\
\hline Usar vocabulário cartográfico específico & NWEA (2017) \\
\hline Incluir sempre que possivel a Rosa dos Ventos & NWEA (2017) \\
\hline $\begin{array}{l}\text { O idioma utilizado deve ser compativel ao } \\
\text { do ledor e candidato }\end{array}$ & NWEA (2017) \\
\hline $\begin{array}{l}\text { Considerar como fatores contextuais ao se projetar um } \\
\text { mapa: mobilidade, visualizaçăo, onde a leitura do mapa ocorre, } \\
\text { tempo, contexto social, interatividade do meio e retórica }\end{array}$ & Perkins (2008) \\
\hline $\begin{array}{c}\text { Fatores culturais devem desempenhar um papel maior } \\
\text { no projeto de representaçöes e interfaces } \\
\text { usadas na geovisualização }\end{array}$ & Perkins (2008) \\
\hline $\begin{array}{l}\text { Os ledores devem ter acesso a atlas } \\
\text { e dicionários como material de apoio }\end{array}$ & Perkins (2008) \\
\hline $\begin{array}{c}\text { Os mapas devem apresentar um tamanho mínimo de } \\
\text { acordo com o diagramação das provas, de maneira } \\
\text { que seja visivel e identificável pelo ledor }\end{array}$ & Ledores $1,2,3$ e 4 \\
\hline $\begin{array}{l}\text { Utilizar mapas quando estritamente } \\
\text { necessário para a resolução da questão }\end{array}$ & Ledores $1,2,3$ e 4 \\
\hline $\begin{array}{l}\text { As provas do ledor e do cego devem ser trabalhadas } \\
\text { individualmente, retirando-se o excesso de artificios visuais } \\
\text { desnecessários presentes na prova comum }\end{array}$ & Ledores 1 e 2 \\
\hline $\begin{array}{l}\text { Tornar obrigatório o curso de capacitação para voluntários } \\
\text { que se inscrevem em processos seletivos públicos que } \\
\text { incluam candidatos com deficiência }\end{array}$ & Ledores le 2 \\
\hline
\end{tabular}




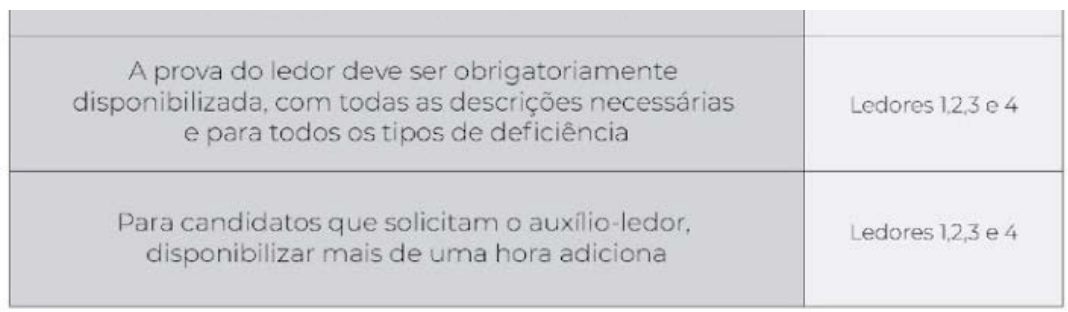

Figura 8 Segunda página do conjunto de recomendações. Fonte: as autoras (2018).

A partir desse primeiro conjunto de recomendações, a quesito de exemplificação da aplicação das recomendações, adequou-se um dos mapas já utilizados pelo ENEM, mantendo-se apenas suas informações textuais. O mapa foi escolhido de maneira aleatória, oriundo do exame de 2009 (BRASIL, 2009), sendo suas alterações demonstradas na Figura 9 a seguir:

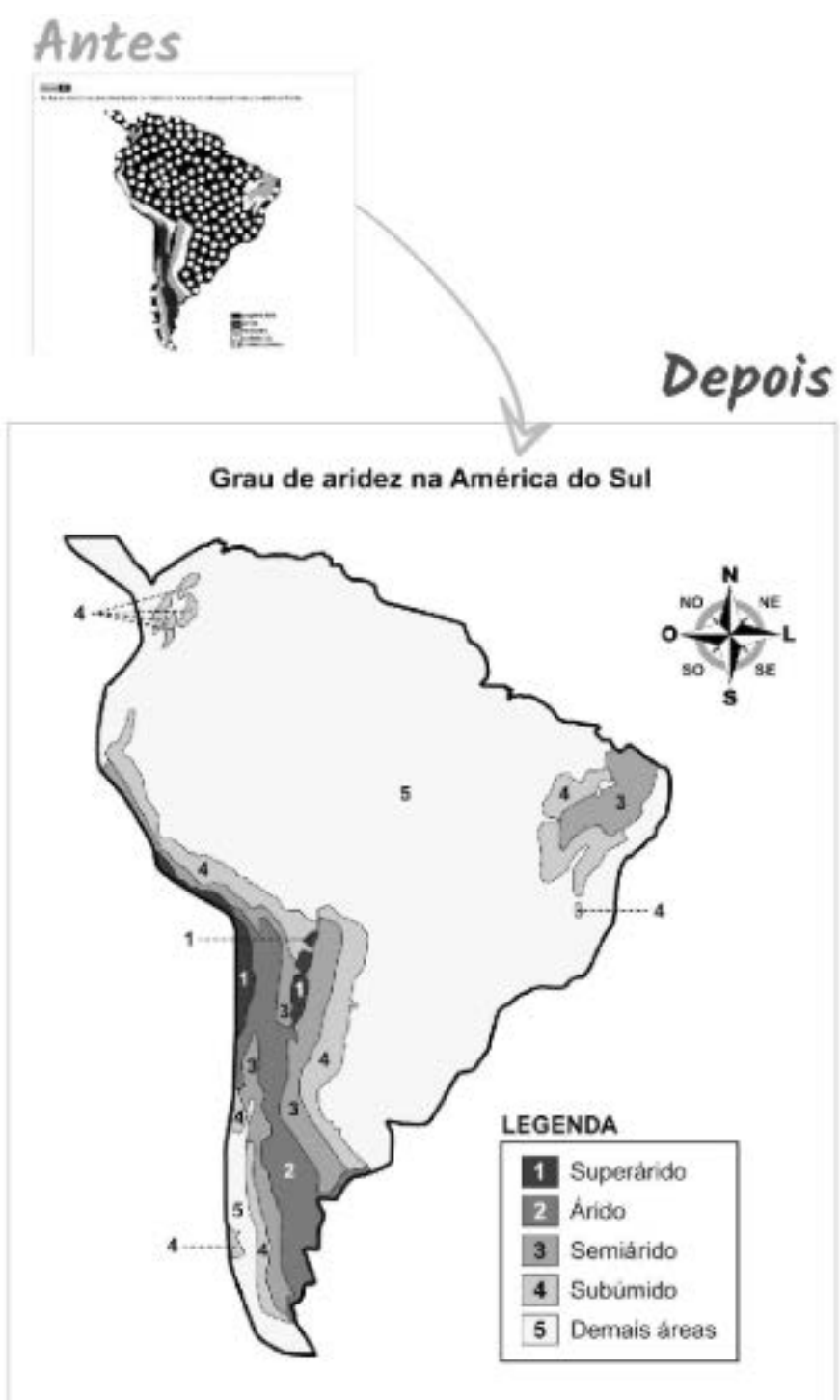

Figura 9 Aplicação das recomendações a um mapa já utilizado pelo ENEM. Fonte: as autoras (2018). 
As seguintes alterações foram realizadas de acordo com as recomendações:

- Eliminaram-se as texturas, por serem similares entre si;

- Por tratar-se de um mapa de representação qualitativa, utilizou-se a cor como variável gráfica para a distinção entre áreas;

- Acrescentou-se a Rosa dos Ventos;

- Inseriu-se título e legenda, de forma a estabelecer uma ordem de apresentação entre as informações do mapa;

Espera-se, com esse primeiro conjunto de recomendações, que seja possível avançar na composição de recomendações precisas para a elaboração de mapas a serem descritos no ENEM. O INEP, responsável pela elaboração da prova, não informa exatamente quem são os responsáveis pela diagramação completa da prova, contudo, o intuito dessa proposta de recomendações é de que possam ser lidas e compreendidas por qualquer profissional do ramo, tanto designers, cartógrafos e até mesmo pedagogos.

\section{Resultados e discussão}

Por fim, como resultado da pesquisa, obteve-se modelo parcial de recomendações para o design de mapas de provas que incluam candidatos cegos. No levantamento teórico, observou-se que a legislação brasileira sobre o direito do cego em processos seletivos é enfática e rigorosa. No entanto, a realidade relatada pelos entrevistados não é alinhada a essa eficácia: cursos de especialização para ledores do ENEM não são suficientes para o trabalho individualizado com os cegos, o tempo para o preparo desse voluntário é insuficiente, e queixas sobre a estrutura e legibilidade das provas se somam.

Dentro dessa problemática de legibilidade da prova, ao se propor recomendações que venham a melhorar o entendimento dos mapas, observou-se a complexidade do processo. Por exemplo, aplicar somente as indicações das variáveis gráficas de Bertin (1983) não seria suficiente, devido ao contexto hibrido em que esses mapas são aplicados. Assim, outros fatores externos a legibilidade das provas e dos mapas merecem atenção para o prosseguimento e aplicação das recomendações, como por exemplo, a disponibilização de um Atlas para a consulta dos ledores durante a descrição.

\section{Conclusão}

Conclui-se com esse trabalho que a aplicação de recomendações para mapas neste contexto é necessária, para que assim mais candidatos cegos possam ter seu acesso à universidade ou a cargos públicos garantidos. No entanto, para o prosseguimento da pesquisa, é 
necessário aprofundamento bibliográfico maior, bem como a consulta a mais especialistas, como cartógrafos e designers. A aplicação das recomendações sobre mapas já existentes também seria fator crucial para sua validação, assim, seria possível medir todos os aspectos que foram abordados, e os que ainda precisam ser. Com a aplicação das recomendações sobre uma quantidade maior de mapas, seria possível também aplicá-los em ambiente simulado, no qual ledores e cegos realizariam a prova, observando-se assim fatores que contribuiriam para o aprofundamento das recomendações.

\section{Referências}

BERTIN, J. 1986. A neográfica e o tratamento gráfico da informação. Tradução de Cecília Maria Westphalen. Curitiba: Ed.UFPR

BERTIN, J. 1983. Semiology of graphics. Madison: The University of Wisconsin Press.

BRASIL. Lei no 8.112. 1990. Dispõe sobre o regime jurídico dos servidores públicos civis da União, das autarquias e das fundações públicas federais. Brasília : Diário Oficial da União, DF.

BRASIL. Decreto no 5.296. 2004. Regulamenta as leis nos 10.048, de 8 de novembro de 2000 , que dá prioridade de atendimento às pessoas que especifica, e 10.098, de 19 de dezembro de 2000, que estabelece normas gerais e critérios básicos para a promoção da acessibilidade das pessoas portadoras de deficiência ou com mobilidade reduzida, e dá outras providências. Brasília: Diário Oficial da União, DF.

BRASIL. Ministério da Educação. Instituto Nacional de Estudos e Pesquisas Educacionais Anísio Teixeira. Exame Nacional do Ensino Médio de 2009. Brasília: INEP/MEC, 2009b.

BRASIL. Ministério da Educação. Instituto Nacional de Estudos e Pesquisas Educacionais Anísio Teixeira. Exame Nacional do Ensino Médio de 2013. Brasília: INEP/MEC, 2013.

CASTRO, S. F. 2011. Ingresso e Permanência de Alunos com Deficiência Visual em Universidades Públicas Brasileiras. Tese (Doutorado em Ciências Humanas) Setor de Educação, Universidade Federal de São Carlos, São Carlos.

FIORINI, M. L. S.; MANZINI, E. J. 2010. Procedimentos para descrição de figuras em texto impresso visando à acessibilidade para pessoas cegas: um estudo a partir de um livro de educação física adaptada. Revista Educação em Questão, v. 38 , n. $24: 164-183$.

GIVEN, L. M. The Sage encyclopedia of qualitative research methods. New York: Sage Publications, 2008.

INEP - INSTITUTO NACIONAL DE ESTUDOS E PESQUISAS EDUCACIONAIS ANÍSIO TEIXEIRA. 2002. ENEM - Exame Nacional do Ensino Médio: documento básico. Brasília: MEC/INEP.

INEP - INSTITUTO NACIONAL DE ESTUDOS E PESQUISAS EDUCACIONAIS ANÍSIO TEIXEIRA. 2016. ENEM 2016: Balanço das Inscrições. Brasília: MEC/ INEP, 2016. 
INEP - INSTITUTO NACIONAL DE ESTUDOS E PESQUISAS EDUCACIONAIS ANÍSIO TEIXEIRA. 2017. ENEM 2017: Balanço das Inscrições. Brasília: MEC/ INEP, 2017.

LOCH, R. E. N. 2008. Cartografia tátil: mapas para deficientes visuais. Portal da Cartografia, v.1, n.1: 35-58.

MACEACHREN, A. M. 1994. Some truth with maps: A primer on symbolization and design. New York: Guilford Press.

NCAM - NATIONAL CENTER FOR ACCESSIBLE MEDIA. 2017. The Carl and Ruth Shapiro Family National Center for Accessible Media.

NWEA - NORTHWEST EVALUATION ASSOCIATION. 2017. NWEA Image Description Guidelines for Assessments: making assessment accessible for all students.

PERKINS, C. 2008. Cultures of map use. The Cartographic Journal, London, v. 45, n. 2: $150-158$.

SANTOS, J. C. 2011. A constituição do enunciado nas provas do ENEM e ENADE: uma análise dos aspectos semiológicos da relação língua-imagem sob a ótica dos estudos do discurso. Dissertação (Mestrado em Linguística) - Centro de Educação e Ciências Humanas, Universidade Federal de São Carlos, São Carlos.

SILVEIRA, F. L.; BARBOSA, M. C. B.; SILVA, R. 2015. Exame Nacional do Ensino Médio (ENEM): uma análise crítica. Revista Brasileira de Ensino de Física, v. 37, n. 1: 1101-1111.

\section{Sobre os Autores}

\section{Fernanda Domingues, mestranda.}

<fernanda.fdomingues@gmail.com>

Graduada em Design pela Universidade Tecnológica Federal do Paraná.

Mestranda e bolsista CAPES pelo Programa de Pós-Graduação em Design da Universidade Federal do Paraná. Endereço: UFPR Edifício Dom Pedro I - R. General Carneiro, 460 - $8^{\circ}$ andar - Curitiba - Paraná - Brasil, CEP: 80060-150.

\section{Claudia Mara Scudelari de Macedo, Dra.}

<claudia.scudelari@gmail.com>

Doutorado em PPG-EGC - Mídia e Conhecimento da UFSC - Possui pesquisas e publicações em multimídia-geometria, ambiente hipermídia, hipermídia adaptativa, Objetos de aprendizagem, Mapas conceituais, Acessibilidade digital. Foi docente da PUC-PR e professora colaboradora do PPGDesign da UFPR.

Artigo recebido em 05/11/2018

Artigo aceito em 08/03/2019 